ఠ

\title{
Functioning and quality of life in Dutch oldest old with diverse levels of dependency
}

This article was published in the following Dove Press journal:

Patient Preference and Adherence

\section{Riaan Botes' \\ Karin M Vermeulen' \\ Antonie M Gerber ${ }^{2}$ \\ Adelita $\vee$ Ranchor ${ }^{3}$ \\ Erik Buskens'}

'Department of Epidemiology, University of Groningen, University Medical Center Groningen, Groningen, the Netherlands; ${ }^{2}$ Department of Basic Medical Sciences (G25), University of the Free State, Basic Medical Sciences, Bloemfontein, South Africa; ${ }^{3}$ Department of Health Psychology, University of Groningen, University Medical Center Groningen, Groningen, the Netherlands
Correspondence: Riaan Botes Department of Epidemiology, University of Groningen, University Medical Center Groningen, PO Box 30.00I, 9700 RB Groningen, the Netherlands Email botesr@umcg.nl
Background: Frequently, a questionnaire like the EQ-5D is applied to investigate elderly health-related quality of life (HRQoL), but current literature suggests that inputs that go beyond these traditional health aspects might be of importance. The capability approach is a different method, which integrates several non-health-related factors to define the well-being of the oldest old.

Objective: We propose to investigate the differences in oldest old functionings and quality of life (QoL), given different levels of dependency, using both a utility-based (EQ-5D+C) and capability-based (Currently Achieved Functioning) questionnaire.

Methods: We interviewed 99 Dutch elderly, living in the Groningen, Veendam, and Hoogeveen areas. The average age of the elderly was 80 years, who were living independently, still looking after themselves; living semi-dependently with moderate care; or living in a nursing home requiring consistent care.

Results: The utility score for the dependent group is the lowest of all three groups, across the diseases investigated in this study. The respective average utility scores calculated for the dependent, semi-dependent, and independent subgroups were 0.56 ( $\mathrm{SD} \pm 0.10$ ); 0.84 ( $\mathrm{SD} \pm 0.11$ ), and 0.69 ( $\mathrm{SD} \pm 0.13$ ). Mobility and pain were reported to be the major domains where problems appeared across the three groups. Additionally, dependent elderly experience deficits in the role and control functionings while the other two subgroups experience deficits in pleasure and security.

Conclusion: The results suggest that it is important to take note of the achievability of functionings and HRQoL, in addition to care dependency, to obtain QoL and well-being outcomes of the oldest old.

Keywords: oldest old, functionings, quality of life, dependency

\section{Introduction}

Elderly quality of life (QoL) is a multidimensional concept that includes psychological, physical, and social dimensions. ${ }^{1-3}$ Apparently, elderly health care poses a unique challenge with various social, psychological, and physical problems occurring at advanced age. ${ }^{4,5}$ Notably, two thirds of Europeans aged over 75 years of age are reporting suboptimal health status. ${ }^{6}$ It is therefore of the utmost importance to address elderly functioning and disability in elderly health care and treatment options. Chronic illness, comorbid disease, income, individual resilience, and social support are factors influencing the well-being of the general population. It is however clear that factors like self-efficacy, perceiving life as meaningful and manageable are important factors to consider when determining elderly health-related quality of life (HRQoL) and functionings. ${ }^{1,7}$ These factors become increasingly pertinent in the elderly, yet how these factors influence the well-being of the oldest old, compared to the general population remains uncertain. ${ }^{8}$

Frequently, a questionnaire like the EQ-5D is applied to investigate HRQoL. Importantly, this instrument was developed with a typical adult middle-aged population 
in mind rather than an elderly individual. Therefore, quite possibly the available instruments are inappropriate for the elderly as standard instruments as these do not include the non-health-related factors mentioned above. ${ }^{9}$ HRQoL is however a generic issue, which should ultimately capture the relevant issues of any individual regardless of age, gender, and cultural background.

To resolve the current mismatch between the instrument's constructs and the target population, the capability approach may provide an alternative. The approach enables various non-health-related factors that determine the wellbeing of the elderly. ${ }^{10}$ Functioning is a part of the capability approach and focuses on what people actually achieve with the resources at their disposal. ${ }^{11}$ However, disease impairs an individual's ability to achieve functionings, thereby reducing an individual's QoL. Subsequently, a state referred to as actual disability is induced. ${ }^{12}$ Previous studies have shown that functioning instruments, like the ICE pop CAPability measure for older people (ICECAP-O), capture a broader range of benefits. Particularly, for the elderly, an important part of the objective of interventions is to generate value beyond HRQoL. ${ }^{13,14}$ Indeed, studies have indicated that there is a causal relationship between changes in functional status and disease status with self-rated health. ${ }^{15}$

Therefore, the importance of understanding how elderly health profiles, based on the level of dependency, disease prevalence, and resource availability, affect the elderly QoL and functionings is obvious for considering health care and treatment choices. Each chronic disease has its own pathway of decreasing QoL. However, resource availability significantly affects the QoL and functionings of the elderly. ${ }^{16,17}$

Resources can be sociodemographic in nature: education, income, living arrangements to personal characteristics, and social support. ${ }^{12}$ They allow individuals to convert unique utility and capability profiles into effective self-management strategies. $^{18}$

Importantly, current literature suggests that additional resources like home care, personal care workers, physiotherapy, and occupational therapy can improve HRQoL and well-being outcomes. ${ }^{19}$ Thus, identifying what the elderly think about prioritization, resource allocations, and successful aging might be of paramount importance when the aim is to adapt health care services according to the views of the elderly. ${ }^{20,21}$

Since there is evidence to suggest that the capability approach will provide complementary information regarding QoL, ${ }^{13}$ the current study will focus on elderly QoL, given different levels of dependency and the effects of prevalent chronic diseases, using an integrated utility- and capabilitybased approach. It is hypothesized that certain diseases and multi-morbidity will cause larger decline in utility and capability and will ultimately have an implicit effect on the achievement of functionings. ${ }^{22}$ In addition, we hypothesize that the absence or presence of certain resources are paramount factors to include in QoL considerations, since resources can be mediating factors that determine the difference between effectively managing a disease and developing potential disability.

\section{Methods}

\section{Subjects and study design}

University Medical Center Groningen (UMCG) has a special interest in healthy aging. As part of this particular focus, elderly in the local, Northern, part of the Netherlands (Groningen, Veendam, and Hoogeveen) were invited to participate in the study. The recruitment process involved telephonically contacting elderly and asking whether they would be willing to participate in the study. Inclusion criteria were age $\geq 65$ years fulfilling one of the following living arrangements: living independently, still looking after themselves; living semi-dependently with moderate care (still able to perform instrumental tasks of daily living with some help for another person); and living in a nursing home requiring consistent care. No specific exclusion criteria were implemented. This is due to the fact that the aim of the study was to include a broad range of respondents with a wide variety of health and non-health deficits, to fully understand the problems that the sample of oldest old Dutch respondents face.

Demographic information of the respondents was gathered. The interviewer recorded the number of chronic disorders, the level of education, number of people in a household, spiritual interests, and multi-morbidity of the respondents via self-report. Spiritual interests were determined by asking whether the respondents viewed themselves as being religious, with a simple yes or no answer. Respondents were asked to report any chronic disorders, read from a list by the interviewer, which included prevalent disorders.

The EQ-5D+C and Currently Achieved Functioning (CAF) questionnaires were used during structured interviews to retrieve the data. Two pilot studies were performed to test the feasibility of the study. Details of the pilots were published and are available in print. ${ }^{23}$ The results from the pilot studies indicated that individuals from different parts of the world are able to complete, describe, and value the EQ-5D+C and CAF questionnaires. We concluded that since the two questionnaires have proven to be feasible in providing 
information on QoL and well-being of elderly people, a comprehensive study should be done, which includes both the EQ-5D+C and the CAF questionnaires.

All respondents completed and signed informed consent to participate in the study. Ethical approval was obtained from the UMCG ethical committee (Metc 2011/041), regarding the procedures and methods used in this study (reference number M11.098466).

Problems reported as limitations in utility and functionings were regarded as respondent's inability to perform at, or achieve relevant QoL and well-being levels. The concept of health and disability, as described in this study, further suggests that resources is a key factor to consider when determining an individual's disability status. When compared to respondents who were achieving QoL and well-being thresholds set by the elderly respondents, the importance of the reported problems becomes relevant. Non obtainment of utility and functionings possibly translates into poorer QoL and actual disability for individuals with sub-optimal performance. This study therefore to a large extent focuses on the problems reported by the independent, semi-dependent, and dependent elderly. Additionally, we gathered sociodemographic information, which may modify the QoL and well-being.

\section{The EQ-5D+C questionnaire}

The EQ-5D+C is a utility instrument, developed by the EuroQol group, and mainly focuses on HRQoL. Domains included in the EQ-5D+C are mobility, self-care, usual activities, pain/discomfort, anxiety/depression, and cognition. This questionnaire is an updated version of the EQ-5D and includes a sixth domain, cognition. ${ }^{24,25}$ For each domain three possible answer categories exist: 1, no problem; 2, moderate problems; and 3 , extreme problems. This part of the EQ-5D+C is used to describe the actual health state of the elderly respondents.

An extract from previously published work describes the validity and applicability of the EQ-5D+C: ${ }^{23}$ We used an extended version (EQ-5D+C) of the standard EQ-5D that included "cognitive functioning" as an additional attribute. The standard EQ-5D classification system developed by the EuroQol Research Foundation (https://euroqol.org/) describes health status according to five attributes: mobility, self-care, usual activities, pain/discomfort, and anxiety/depression. Each attribute has three levels: "no problems" ("1"), "some problems" (“2”), and "severe problems" (“3”). Health state descriptions are constructed by choosing one level for each attribute (eg, the best health state is represented by 11111).
The non-standard EQ-5D+C is similar to the EQ-5D, but with a three-level cognition attribute added. Of specific relevance to the elderly are health aspects such as vision and hearing, and in particular cognition. The addition of the cognition domain makes the EQ-5D+C of specific importance to the elderly, since aging is to a degree associated with a decline in cognitive ability. The proportion of respondents reporting some problems and extreme problems was calculated, within each subgroup, in each of the EQ-5D+C domains. The EQ-5D+C/ utility scores for each subgroup, type of disease (hypertension, heart disease, diabetes, psychological disorder, joint disorder) were calculated. Since an algorithm for the EQ-5D+C questionnaire or ICECAP-O questionnaire is lacking for the Dutch population, the overall utility scores were calculated using the Dolan (UK) EQ-5D algorithm. The latter does not presently include the cognition domain. ${ }^{26}$ The authors however included the cognition domain to evaluate if the subgroups of elderly show differences between cognitive abilities, when evaluating their own health descriptions. Typically algorithms are used to provide a value that represents the utility assigned to a health/disease state by a certain group of respondents. These utility values can be used to calculate quality-adjusted life years for the respondents providing the utility scores. In this paper, scores below the subgroup mean were regarded as contributing to poorer QoL. ${ }^{27}$ This was done to explicitly focus on the factors significantly influencing elderly QoL.

SPSS version 16 was used to perform the sum score calculations. All the other calculations were performed using Microsoft Excel.

\section{CAF questionnaire}

The CAF questionnaire is theoretically rooted in the capability approach. ${ }^{10}$ The capability approach promotes the idea that every individual strives to be or do something. The two major components of this approach, functionings and capabilities, are one's achieved doings and beings (functionings) and one's ability to achieve certain functionings (capabilities). ${ }^{28}$ Grewal et al embarked on a two-stage analysis to first determine factors that contribute to the quality of elderly informant's lives and second to identify attributes of QoL. ${ }^{29}$ From this study five attributes emerged: attachment, enjoyment, security, role, and control. Table S1 summarizes the aspects that contribute and determine these attributes.

Coast et al further investigated this issue by performing qualitative and quantitative work on these five attributes. ${ }^{30}$ The qualitative work focused on the design of a measurement instrument, while the quantitative work focused on the validation of the measurement instrument. Ultimately an 
instrument to determine the effect of health and social care interventions was presented while mentioning the potential of the instrument in economic evaluation of interventions. ${ }^{30}$

The CAF questionnaire used the five attributes to investigate elderly functionings. Pilot studies were performed in the Netherlands and in South Africa to test the feasibility and validity of the CAF questionnaire. The results of the pilot studies showed that individuals from different subgroups, and even different parts of the world, indicated that they were able to complete, describe, and value the CAF questionnaire.

\section{Statistical analysis}

Statistical analysis performed on the results included determining utility scores of the five most prevalent diseases (Figure 1), using the Dolan (UK) EQ-5D algorithm. ${ }^{26}$ Although the algorithm does not include the cognition domain, the addition of the cognition domain can provide valuable descriptive information on the cognitive status of the respondents. Typically, this rating scale is used to measure general health. Scores closer to 1 indicate better HRQoL and scores closer to 0 indicate worse HRQoL.

Statistical analysis was performed on the descriptive data obtained from both the questionnaires. Respondents reporting problems in domains or attributes, of both the questionnaires, were evaluated to determine the percentages of respondents reporting problems in achieving HRQoL and well-being outcomes. The results of this descriptive analysis are presented in Figures 2 and 3 respectively.

Descriptive statistical analysis was performed on the demographic data (Table 1 ) and the $P$-values calculated using the chi-square test.

\section{Results \\ Respondents}

The total sample of the study comprises 99 respondents. The average age of the elderly was 80 years, 29 living independently, still looking after themselves; 30 living semidependently with moderate care; and 40 living in a nursing home requiring consistent care.

Table 1 describes the sociodemographic variables for the three groups. The majority of the respondents were female. Only the dependent group reported that they had more than two people in the household. The disease profiles for all three groups appear to be similar with the exception of the dependent elderly reporting higher prevalence of heart disease and stroke and fewer psychological disorders.

\section{EQ-5D+C domain scores and utility scores}

The respective average utility scores calculated for the dependent, semi-dependent, and independent subgroups were 0.56 ( $\mathrm{SD} \pm 0.10), 0.84$ ( $\mathrm{SD} \pm 0.11$ ), and 0.69 ( $\mathrm{SD} \pm 0.13$ ).

Figure 1 presents the utility scores calculated for respondents suffering from psychological disorders, heart disease, joint disorders, diabetes, and hypertension. The authors included these five diseases, as these were the most prevalent in the sample of elderly.

The utility scores calculated for the dependent, semidependent, and independent subgroups suffering from psychological disorders, heart disease, joint disorders, diabetes, or hypertension are all below the average utility scores of the respective subgroups.

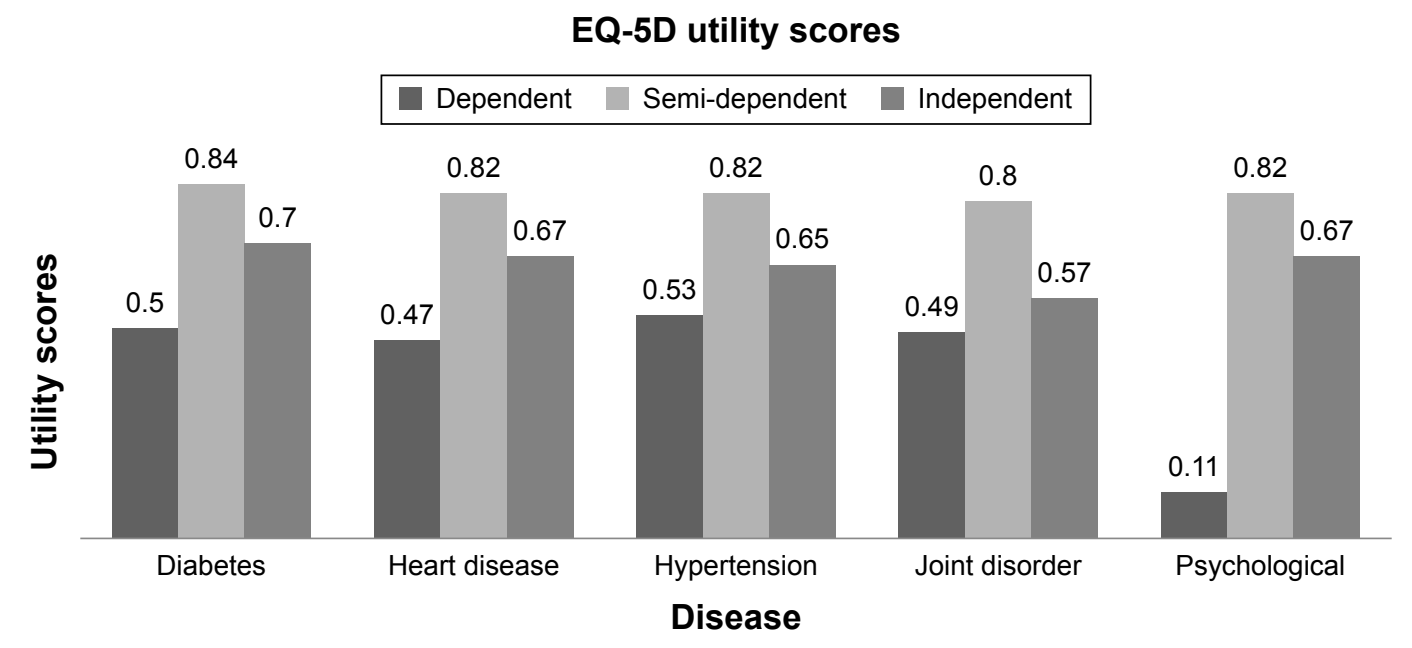

Figure I EQ-5D utility scores. 


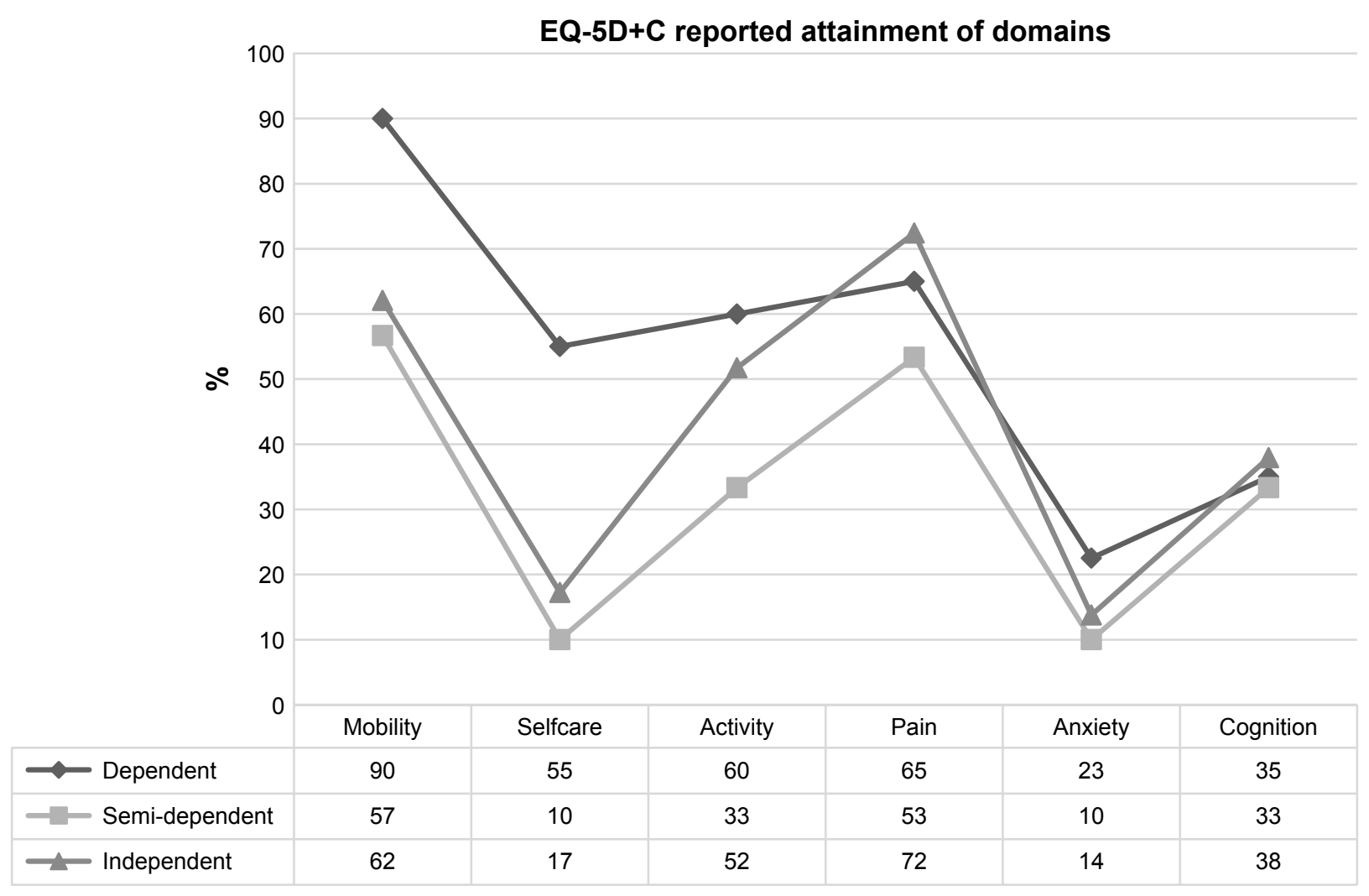

Figure 2 EQ-5D+C reported attainment of domains for three subgroups of elderly.

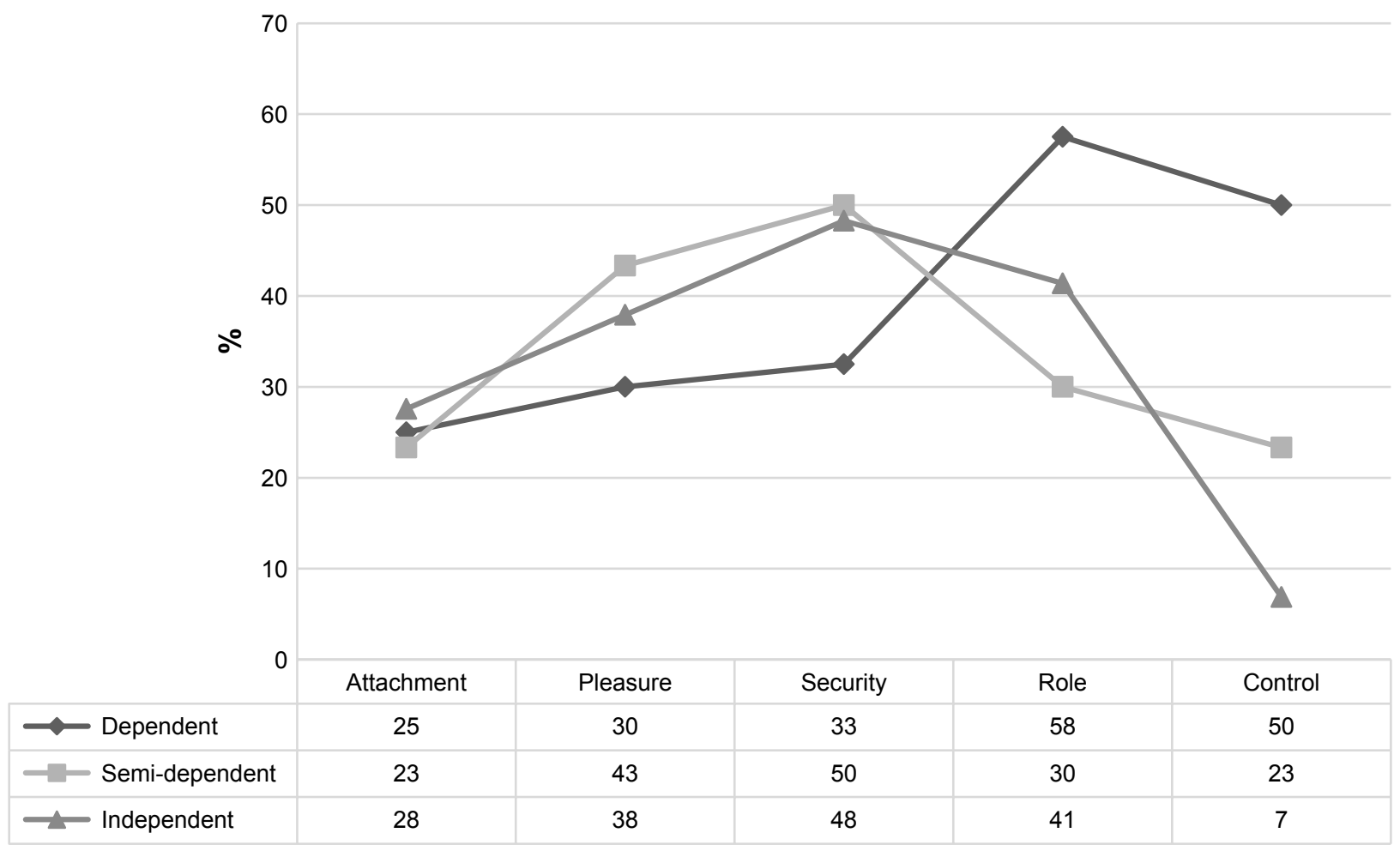

Figure 3 Reported achievements of functionings. 
Table I Sociodemographic and disease variables

\begin{tabular}{|c|c|c|c|c|c|}
\hline & $\begin{array}{l}\text { Dependent } \\
n=40\end{array}$ & $\begin{array}{l}\text { Semi-dependent } \\
n=30\end{array}$ & $\begin{array}{l}\text { Independent } \\
\mathrm{n}=\mathbf{2 9}\end{array}$ & P-values & $\begin{array}{l}\text { Significance of } P \text {-values } \\
\text { between subgroups }\end{array}$ \\
\hline Age (years), mean [range] & 87 [81-93] & 83 [75-89] & 80 [69-87] & NS & \\
\hline Female, n (\%) & $33(83)$ & $21(70)$ & $22(76)$ & NS & \\
\hline $\begin{array}{l}\text { Education, } \mathrm{n}(\%) \\
\text { Primary } \\
\text { Secondary } \\
\text { Vocational training } \\
\text { Higher education/university } \\
\text { Other }\end{array}$ & $\begin{array}{l}13(33) \\
9(23) \\
13(33) \\
5(13)\end{array}$ & $\begin{array}{l}12(40) \\
8(27) \\
8(27) \\
2(7)\end{array}$ & $\begin{array}{l}10(34) \\
10(34) \\
5(17) \\
3(10) \\
1(3)\end{array}$ & $\begin{array}{l}\text { NS } \\
\text { NS } \\
\text { NS } \\
\text { NS } \\
\text { NS }\end{array}$ & \\
\hline Spiritual interest, yes, n (\%) & $21(53)$ & $16(53)$ & $13(45)$ & NS & \\
\hline $\begin{array}{l}\text { Number of people in } \\
\text { household, } \mathrm{n}(\%) \\
\text { I } \\
2 \\
3\end{array}$ & $\begin{array}{l}\text { I2 (30) } \\
\text { II (28) } \\
\text { I7 (43) }\end{array}$ & $\begin{array}{l}17(57) \\
13(43) \\
0\end{array}$ & $\begin{array}{l}20(69) \\
9(3 I) \\
0\end{array}$ & $\begin{array}{l}\text { NS } \\
\text { NS } \\
<0.01\end{array}$ & $\begin{array}{l}\text { Dependent/independent and } \\
\text { dependent/semi-dependent }\end{array}$ \\
\hline $\begin{array}{l}\text { Number of diseases, n (\%) } \\
0 \\
1 \\
2 \\
3 \\
4 \\
5 \\
6\end{array}$ & $\begin{array}{l}4(10) \\
12(30) \\
9(23) \\
8(20) \\
3(8) \\
4(10) \\
0\end{array}$ & $\begin{array}{l}5(17) \\
6(20) \\
6(20) \\
8(27) \\
2(7) \\
3(10) \\
0\end{array}$ & $\begin{array}{l}3(10) \\
8(28) \\
5(17) \\
7(24) \\
2(7) \\
3(10) \\
1(3)\end{array}$ & $\begin{array}{l}\text { NS } \\
\text { NS } \\
\text { NS } \\
\text { NS } \\
\text { NS } \\
\text { NS } \\
\text { NS }\end{array}$ & \\
\hline $\begin{array}{l}\text { Disease type, n (\%) } \\
\text { COPD } \\
\text { Heart disease } \\
\text { Hypertension } \\
\text { Stroke } \\
\text { Kidney/gall stones } \\
\text { Kidney disorder } \\
\text { Diabetes } \\
\text { Joint disorders } \\
\text { Epilepsy } \\
\text { Cancer } \\
\text { Psychological disorder }\end{array}$ & $\begin{array}{l}3(8) \\
14(35) \\
25(63) \\
8(20) \\
3(8) \\
1(3) \\
6(15) \\
20(50) \\
1(3) \\
3(8) \\
2(5)\end{array}$ & $\begin{array}{l}2(7) \\
2(7) \\
18(60) \\
4(13) \\
3(10) \\
0 \\
9(30) \\
16(53) \\
1(3) \\
4(13) \\
6(20)\end{array}$ & $\begin{array}{l}5(17) \\
3(10) \\
17(59) \\
1(3) \\
4(14) \\
1(3) \\
5(17) \\
17(59) \\
1(3) \\
5(17) \\
9(31)\end{array}$ & $\begin{array}{l}\text { NS } \\
<0.01 \\
\text { NS } \\
0.06 \\
\text { NS } \\
\text { NS } \\
\text { NS } \\
\text { NS } \\
\text { NS } \\
\text { NS } \\
\text { NS }\end{array}$ & $\begin{array}{l}\text { Dependent/independent and } \\
\text { dependent/semi-dependent } \\
\text { Dependent/independent only }\end{array}$ \\
\hline
\end{tabular}

Note: Significance level $P \leq 0.05$.

Abbreviation: NS, not significant.

The utility score for the dependent group is the lowest of all three groups, across all diseases investigated in this study. The utility scores for the semi-dependent group are the highest of the three groups, across diseases. Notably the semi-dependent and independent groups with joint disorder returned the lowest utility scores of 0.80 and 0.57 , respectively. In the dependent group, however, psychological disorder resulted in the lowest utility score of 0.11 . This result was due to the fact that only two respondents reported psychological disorder with apparently very low scores. Excluding this result would move heart disease into the lowest position for the dependent elderly.

When ranking the domains on specific reported problems, from high to low, it is evident from the results that the dependent group ranked the domains as follows: mobility, pain, daily activity, self-care, cognition, and anxiety (Figure 2). The semi-dependent group ranked the reported problems across the domains as follows: mobility, pain, daily activity/cognition, and self-care/anxiety. And lastly, the independent group rated the reported problems in the domains as follows: mobility, pain, cognition, daily activity, self-care, and anxiety. Notably the dependent elderly also reported the most problems in achieving positive outcomes across all domains investigated.

\section{The CAF questionnaire}

The results of the CAF questionnaire indicated that the dependent elderly group investigated in the study reported 
the most problems in achieving their functionings. The results of the currently achieved capabilities questionnaire are summarized in Figure 3.

When ranking the problems experienced with their functionings, from high to low, the dependent group ranked their problems as follows: role, control, security/pleasure, and attachment. The semi-dependent group ranked their problems in achieving functionings in the following order: security, pleasure, role, and control/attachment. Lastly, the independent group ranked their problems as: security/ pleasure, role, attachment, and control.

\section{Discussion}

The results of the utility scores calculated from the EQ-5D+C questionnaire indicated that suffering from any of the five diseases, psychological disorders, heart disease, joint disorders, diabetes, and hypertension, relegates the oldest old to positions of suboptimal utility. This result corroborates previous studies indicating that diseases do play a significant role in determining QoL and might be of specific importance for the oldest old individuals. ${ }^{15}$

The finding also suggests that the five diseases will consign all the subgroups to potential disability. It is, however, important to note differences in utility score between the groups. Clearly it is found that not only the prevalent disease but also other health and non-health factors determine the functional status. In line with this fact, the results indicate that mobility and pain were the major domains, across the three groups, resulting in most problems reported. Recurring problems with mobility and persistent pain can certainly influence the functional status of an individual with negative consequences. Additionally, the high prevalence of joint disorders in all three subgroups appears to be a relevant factor to recognize. ${ }^{31}$ This result is also in line with previous studies indicating that musculoskeletal disorder has a significant negative impact on elderly physical as well as mental health. ${ }^{32}$

The dependent elderly reported the lowest utility score, indicating they are struggling with disability. The dependent elderly also reported that they had the most problems in obtaining the mobility functioning. In part this may be attributable to the fact that they often had suffered a stroke, which has been indicated to have a high disabling impact. ${ }^{31}$ A non-fatal stroke regularly causes disability such as mobility limitations.

Additionally, from the functioning results, it is clear that the dependent elderly is the group struggling to achieve the role and control functionings. The fact that the dependent elderly suffer from a higher prevalence of heart disease can be a possible explanation for the deficit in role achievement. ${ }^{33}$ All these factors taken together might impact on the ability of the dependent group to be in control of their lives and to be self-sufficient. ${ }^{34}$

The semi-dependent and independent groups are possibly concerned about the status of the health and finances since both the groups reported that security, which includes monetary concerns and health, is affected considerably. Furthermore, literature suggests that impairment in leisure activities is related to "lower levels of symptom management and less active coping behavior." 35 The semi-dependent group however had the highest utility scores suggesting that the semi-dependent group is already in a transition phase of their health. Being semi-dependent might be the most comfortable place to be regarding health outcomes, since the reality of a decline in health is apparent to the semi-dependent group, although they can still perform certain tasks and remain in control of their lives. ${ }^{36}$

Importantly, contrary to other studies, the findings indicate that the independent elderly experience better functioning in the presence of chronic disease when compared to dependent elderly. ${ }^{37}$ This result indicates that within the oldest old group there are subgroup differences, further strengthening the idea that well-being is an individualized concept with resource and disease interactions at various levels.

The major difference in sociodemographic resources between the groups was the fact that more than two people were living in the dependent elderly's household. We hypothesize that a possible mediating factor might be the fact that the dependent elderly need constant assistance of a care worker. This can certainly diminish one's autonomy and the ability to be in control of one's life. ${ }^{34}$

Finally, all the subgroups rated anxiety as the aspect that was least burdensome. The dependent group rated attachment as the functioning with which they had the least trouble achieving, while the semi-dependent and independent groups rated control as the functioning with which they had the least trouble achieving. We hypothesize that this fact in itself can be a mediating factor and can be transformed into a resource. The autonomy factor of control and the absence of significant anxiety levels can empower the semi-dependent and independent elderly to experience less disability, when compared to the dependent elderly. ${ }^{1}$ How the dependent elderly experience less trouble in achieving the attachment, pleasure, and security functionings is unclear. It is plausible that dependent elderly feel that, given the worse QoL and well-being experience, the achieved levels of attachment, 
pleasure, and security remain acceptable, while deficits in control and a purpose in life are not acceptable.

The implications of the results suggest that although disease does affect QoL and well-being, the achievability of health domains and functionings can enhance or impair the development of disability.

The influence of a disease is not the same for all groups and should be considered in conjunction with other mediating factors to determine disability. Health and disability is a highly individualized concept, with disease profiles, available resources, and achieved health domains and functionings impacting on the ability of the oldest old to manage and cope with disability.

Assisting the elderly groups, based on dependency levels, for instance, in achieving these resources could then allow for concepts like equity and self-efficacy to be embedded into elderly care programs. Achieved health or non-health factors, acting as resources, empower each individual with various pathways to achieve personal QoL and well-being goals. This could possibly translate into a societal benefit in terms of health resource utilization and prevention of early disability.

This information must be relayed to the elderly patient, so that they can formulate informed and effective health care choices. ${ }^{38}$

The results however do indicate that addressing deficits in health-related issues such as mobility and pain experience remain universal issues that the oldest old face. Addressing these two critical aspects of daily life can have a positive impact on non-health-related aspects that determine the overall well-being.

Effective pain management and adequate mobility are certainly essential for the achievement of other health-related and non-health-related domains that determine QoL and well-being. As such, tailored programs aimed at preventing disease, causing mobility limitations, and effectively managing pain should be an important priority for health care services.

The study has a few limitations. First, the CAF questionnaire is a conceptual questionnaire and was not yet validated for its present use. However, the pilot studies performed confirmed the feasibility of the CAF questionnaire for use in our study.

Second, although evidence supports the idea of using suboptimal utility attached to certain diseases to describe QoL, it is not a standard practice and must be interpreted with other factors as mentioned in the paper. ${ }^{39}$ Finally, since this study was performed in the Northern part of the Netherlands and with a limited number of respondents, future studies must include more respondents and include more Dutch provinces to further support the inferences made by this study. Amid these limitations, the strength of this study is substantial since important findings were corroborated whereas also new associations were found. A considerable and expanding body of evidence exists to support the results and findings of this study.

It is clear that when comparing elderly based on three dependency levels, the oldest old dependent elderly are a group at risk of experiencing considerable problems in health and well-being outcomes.

It is therefore important to understand how prevailing quality of life unique to a group, region or population interacts with the available resources to promote wellbeing. Health, disability, and resource utilization is however a very personal endeavor that translates into the ability or inability of people to manage and succeed on physical, emotional, and social arenas.

\section{Acknowledgments}

This study was funded by the University of Groningen as part of a PhD project. The funder had no role in the design of the study, data collection, analysis, and interpretation of data nor in writing the manuscript.

\section{Disclosure}

The authors report no conflicts of interest in this work.

\section{References}

1. Bowling A, Iliffe S. Psychological approach to successful ageing predicts future quality of life in older adults. Health Qual Life Outcomes. 2011;9:13.

2. Kamaruzzaman S, Ploubidis GB, Fletcher A, Ebrahim S. A reliable measure of frailty for a community dwelling older population. Health Qual Life Outcomes. 2010;8:123.

3. Lim LS, Chutka DS. Preventive medicine beyond 65. Geriatrics and Gerontology International. 2006;6(2):73-81.

4. Arai H, Ouchi Y, Yokode M, et al. Toward the realization of a better aged society: messages from gerontology and geriatrics. Geriatr Gerontol Int. 2012;12(1):16-22.

5. Phelan EA, Anderson LA, Lacroix AZ, Larson EB. Older adults' views of "successful aging" - how do they compare with researchers' definitions? J Am Geriatr Soc. 2004;52(2):211-216.

6. König HH, Heider D, Lehnert T, et al. Health status of the advanced elderly in six European countries: results from a representative survey using EQ-5D and SF-12. Health Qual Life Outcomes. 2010;8:143.

7. Bruscia K, Shultis C, Dennery K, Dileo C. Predictors of quality of life in hospitalized cardiac patients. J Health Psychol. 2008;13(8):982-987.

8. Mertens VC, Bosma H, Groffen DA, van Eijk JT. Good friends, high income or resilience? What matters most for elderly patients? Eur $J$ Public Health. 2012;22(5):666-671. 
9. Bernert S, Fernández A, Haro JM, et al. Comparison of different valuation methods for population health status measured by the EQ-5D in three European countries. Value Health. 2009;12(5):750-758.

10. Coast J, Peters TJ, Natarajan L, Sproston K, Flynn T. An assessment of the construct validity of the descriptive system for the ICECAP capability measure for older people. Qual Life Res. 2008;17(7):967-976.

11. Anand P. Capabilities and health. J Med Ethics. 2005;31(5):299-303.

12. Mitra S. The Capability Approach and Disability. J Disabil Policy Stud. 2006;16(4):236-247.

13. Davis JC, Liu-Ambrose T, Richardson CG, Bryan S. A comparison of the ICECAP-O with EQ-5D in a falls prevention clinical setting: are they complements or substitutes? Qual Life Res. 2013;22(5):969-977.

14. Makai P, Brouwer WB, Koopmanschap MA, Stolk EA, Nieboer AP. Quality of life instruments for economic evaluations in health and social care for older people: a systematic review. Soc Sci Med. 2014;102:83-93.

15. Galenkamp H, Braam AW, Huisman M, Deeg DJ. Seventeen-year time trend in poor self-rated health in older adults: changing contributions of chronic diseases and disability. Eur J Public Health. 2013;23(3):511-517.

16. Cuijpers $P$, van Lammeren $P$, Duzijn B. Relation between quality of life and chronic illnesses in elderly living in residential homes: a prospective study. Int Psychogeriatr. 1999;11(4):445-454.

17. van Jaarsveld CH, Sanderman R, Ranchor AV, Ormel J, van Veldhuisen DJ, Kempen GI. Gender-specific changes in quality of life following cardiovascular disease: a prospective study. J Clin Epidemiol. 2002;55(11):1105-1112.

18. Huber M, van Vliet M, Giezenberg M, et al. Towards a 'patient-centred' operationalisation of the new dynamic concept of health: a mixed methods study. BMJ Open. 2016;6(1):e010091.

19. Comans TA, Peel NM, Gray LC, Scuffham PA. Quality of life of older frail persons receiving a post-discharge program. Health Qual Life Outcomes. 2013;11:58.

20. Diederich A, Swait J, Wirsik N. Citizen participation in patient prioritization policy decisions: an empirical and experimental study on patients' characteristics. PLoS One. 2012;7(5):e36824.

21. Holzmueller CG, Wu AW, Pronovost PJ. A framework for encouraging patient engagement in medical decision making. J Patient Saf. 2012;8(4):161-164.

22. Rijken M, van Kerkhof M, Dekker J, Schellevis FG. Comorbidity of chronic diseases: effects of disease pairs on physical and mental functioning. Qual Life Res. 2005;14(1):45-55.

23. Botes R, Vermeulen KM, Ranchor AV, Buskens E. Functional health state description and valuation by people aged 65 and over: a pilot study. BMC Geriatr. 2018;18(1):11.

24. Krabbe PF, Stouthard ME, Essink-Bot ML, Bonsel GJ. The effect of adding a cognitive dimension to the EuroQol multiattribute health-status classification system. J Clin Epidemiol. 1999;52(4):293-301.

25. Lamers LM, Mcdonnell J, Stalmeier PF, Krabbe PF, Busschbach JJ. The Dutch tariff: results and arguments for an effective design for national EQ-5D valuation studies. Health Econ. 2006;15(10):1121-1132.
26. Dolan P, Shaw R, Tsuchiya A, Williams A. QALY maximisation and people's preferences: a methodological review of the literature. Health Econ. 2005;14(2):197-208.

27. Arnold R, Ranchor AV, Sanderman R, Kempen GI, Ormel J, Suurmeijer TP. The relative contribution of domains of quality of life to overall quality of life for different chronic diseases. Qual Life Res. 2004;13(5):883-896.

28. Welch Saleeby P. Applications of a Capability approach to disability and the International Classification of Functioning, Disability and Health (ICF) in social work practice. J Soc Work Disabil Rehabil. 2006;6(1-2):217-232

29. Grewal I, Lewis J, Flynn T, Brown J, Bond J, Coast J. Developing attributes for a generic quality of life measure for older people: preferences or capabilities? Soc Sci Med. 2006;62(8):1891-1901.

30. Coast J, Flynn TN, Natarajan L, et al. Valuing the ICECAP capability index for older people. Soc Sci Med. 2008;67(5):874-882.

31. Klijs B, Nusselder WJ, Looman CW, Mackenbach JP. Contribution of chronic disease to the burden of disability. PLoS One. 2011;6(9):e25325.

32. Putrik P, Ramiro S, Chorus AM, Keszei AP, Boonen A. Socioeconomic inequities in perceived health among patients with musculoskeletal disorders compared with other chronic disorders: results from a crosssectional Dutch study. RMD Open. 2015;1(1):e000045.

33. Barbareschi G, Sanderman R, Kempen GI, Ranchor AV. Socioeconomic status and the course of quality of life in older patients with coronary heart disease. Int J Behav Med. 2009;16(3):197-204.

34. Dijkstra A, Hakverdioğlu G, Muszalik M, Andela R, Korhan EA, Kędziora-Kornatowska K. Health related quality of life and care dependency among elderly hospital patients: an international comparison. Tohoku J Exp Med. 2015;235(3):193-200.

35. van Houtum L, Rijken M, Groenewegen P. Do everyday problems of people with chronic illness interfere with their disease management? BMC Public Health. 2015;15:1000.

36. Ranchor AV, Wardle J, Steptoe A, Henselmans I, Ormel J, Sanderman R. The adaptive role of perceived control before and after cancer diagnosis: A prospective study. Soc Sci Med. 2010;70(11):1825-1831.

37. Galenkamp H, Deeg DJ, Huisman M, Hervonen A, Braam AW, Jylhä M. Is self-rated health still sensitive for changes in disease and functioning among nonagenarians? J Gerontol B Psychol Sci Soc Sci. 2013;68(5):848-858.

38. Bayliss EA, Edwards AE, Steiner JF, Main DS. Processes of care desired by elderly patients with multimorbidities. Fam Pract. 2008; 25(4):287-293.

39. Netuveli G, Pikhart H, Bobak M, Blane D. Generic quality of life predicts all-cause mortality in the short term: evidence from British Household Panel Survey. J Epidemiol Community Health. 2012 66(10):962-966 


\section{Supplementary materials}

Table SI Description of the five attributes as proposed by Grewal et al'

\begin{tabular}{|l|l|}
\hline Attachment & Feelings of love, affection, companionship, and friendship from your partner, family, friends, and pets \\
\hline Enjoyment & Participation in personal and group activities that is a source of pleasure and joy \\
\hline Security & Feeling safe and secure, not feeling helpless when you consider factors like your finances and your health \\
\hline Role & Having a purpose that provides you with a sense of value \\
\hline Control & You feel independent and you make your own decisions \\
\hline
\end{tabular}

\section{Reference}

1. Grewal I, Lewis J, Flynn T, Brown J, Bond J, Coast J. Developing attributes for a generic quality of life measure for older people: preferences or capabilities? Soc Sci Med. 2006;62(8):1891-1901.

\section{Publish your work in this journal}

Patient Preference and Adherence is an international, peer-reviewed, open access journal that focuses on the growing importance of patient preference and adherence throughout the therapeutic continuum. Patient satisfaction, acceptability, quality of life, compliance, persistence and their role in developing new therapeutic modalities and compounds to optimize clinical outcomes for existing disease states are major areas of interest for the journal. This journal has been accepted for indexing on PubMed Central. The manuscript management system is completely online and includes a very quick and fair peer-review system, which is all easy to use. Visit http://www. dovepress.com/testimonials.php to read real quotes from published authors.

Submit your manuscript here: http://www.dovepress.com/patient-preference-and-adherence-journal 